\title{
Preparation and Properties of Polyamines: Part II-Controlled and Sustained Release of Nitric Oxide (NO) from Nitrosated Polymers
}

\author{
By Jie WANG, ${ }^{1}$ Yu-Han TENG, ${ }^{2}$ Yu HAO, ${ }^{3}$ Justin OH-LEE, ${ }^{4, *}$ and Dillip K. MOHANTY ${ }^{3, *}$
}

The secondary amine moieties of polyamines prepared by the reactions of aliphatic diamines, and 1,5-difluoro-2,4dinitrobenzene, were nitrosated using sodium nitrite and aqueous concentrated sulfuric acid at low temperature. Released NO from these polymers, suspended in water or phosphate buffer solutions (PBS), was measured at increasing time intervals by colorimetric techniques using Griess Reagent. Similar tests were also conducted with model compounds. In general, both the model compounds and the corresponding polymers exhibited similar NO release profiles, with apparent half lives up to $88 \mathrm{~h}$ and $81 \mathrm{~h}$, respectively. They were strongly dependent on the length of the alkyl chains derived from the primary amines used for the preparation of these NO-releasing materials. Results from in vitro studies using low molecular weight NO-releasing compounds with PC-12 cell are also reported. High concentration of NO induced neuronal cell death. On the other hand, low concentration of NO inhibited cell death induced by oxidative stress. This suggests that cell survival effect is NO-dependent. KEY WORDS: Nitrosated Polyamines / Nitric Oxide / Controlled Release / Cell Culture /

Nitrogen monoxide, NO, more commonly known as nitric oxide, plays a critical role in a variety of biological functions. $^{1-3}$ Towards the end of 1987, the discovery that mammalian cells synthesize nitric oxide, which regulates virtually every critical cellular function, has led to an explosion of research activities. ${ }^{4,5}$ For example, NO, which is produced from the amino acid L-Arginine in vivo, is involved in the regulation of neurotransmissions, blood pressure, and immune response. ${ }^{6}$ Nitric oxide can exist as a radical, $\mathrm{NO}^{\bullet}$, as a positively charged ion, $\mathrm{NO}^{+}$(nitrosonium ion), and as nitroxyl anion $\left(\mathrm{NO}^{-}\right){ }^{7}$ This allows $\mathrm{NO}$ to participate in numerous important biological functions mentioned above as well as others. Diseased states ensue when the bioavailability of NO, for a variety of reasons, becomes impaired. ${ }^{8,9}$ Exogenous $\mathrm{NO}$, derived from various families of NO-donors, has been used to ameliorate debilitating symptoms of a few of these diseases. $^{10}$

A vast majority of NO-donors are low molecular weight compounds including: nitrates, nitrites, $N$-nitroso, $C$-nitroso, certain heterocycles, metal-NO complexes, and diazeniumdiolates. ${ }^{10}$ Depending on the chemical nature of these compounds, NO is released spontaneously either in the presence or the absence of a catalyst. In the case of diazeniumdiolates, half-life of NO generation can be varied between $2 \mathrm{~s}$ to $56 \mathrm{~h}$ by changing the nature of the backbone to which the diazenuimdiolate moiety is attached. ${ }^{11}$

In contrast to the low molecular weight NO-donors, which have been investigated extensively, polymeric NO donors are new arrivals in this field. Since NO is known to prevent platelet aggregation, ${ }^{12}$ NO generating polymers can be used as biomaterials, which are likely to come in contact with blood. In addition, the biocompatibility of implanted chemical sensors can be enhanced significantly by using NO-releasing polymers as a coating material. ${ }^{13}$

We have reported the preparation and properties of polymeric and model secondary amines. ${ }^{14}$ The polymers were prepared from a series of homologous aliphatic diamines and the activated dihalide, 1,5-difluoro-2,4-dinitrobenzene (DFDNB) by nucleophilic aromatic substitution reactions in diphenyl sulfone at elevated temperatures. Reactions of DFDNB with two equivalents of homologous monoamines resulted in the formation of the desired model compounds. We report herein the nitrosation of the model compounds and the corresponding polymers to prepare materials containing nitrosamine moieties. These nitrosamines release NO at room temperature in three distinct stages, with varying rates, when they are suspended in PBS. NO release continued up to $30 \mathrm{~d}$, at which point measurements were discontinued. ${ }^{15}$

Recent research posits that, depending on neuronal environments and redox states of NO donor compounds, NO can initiate and mediate either neuroprotection or neurotoxicity. ${ }^{16,17}$ A number of experiments, most of which use inhibitors of endogenous inducible nitric oxide synthase (iNOS) in 1methyl-4-phenyl-1,2,3,6-tetrahydropyridine (MPTP) or transgenic Parkinson disease (PD) model, suggest that endogenous NO reacts with superoxide to produce neuronal oxidative stress leading to toxicity. ${ }^{18}$ Yet a variety of exogenous NO donors have been shown to produce neuroprotective effects via

\footnotetext{
${ }^{1}$ Dendritic Nanotechnology Inc., Mount Pleasant, MI-48858, USA

2Department of Chemistry, Stony-Brook University, Stony-Brook, NY-11794, USA

${ }^{3}$ Department of Chemistry, Central Michigan University, Mount Pleasant, MI-48859, USA

${ }^{4}$ Department of Neuroscience, Central Michigan University, Mt. Pleasant, MI-48859, USA

*To whom correspondence should be addressed (Fax: 989-774-3883, E-mail: Mohan1dk@cmich.edu).
} 
nitrosation (NO+) chemistry. ${ }^{19,20}$ In fact, recent in vitro and in vivo studies show that exogenous nitric oxide can act as a free radical scavenger and protect neurons (including dopaminergic neurons) from oxidative injury. ${ }^{21,22}$ Although the molecular mechanisms of how exogenous NO donors contribute to neuroprotection are not completely understood, studies have shown that NO may confer neuroprotection by a variety of mechanisms. ${ }^{23-28}$ More recent studies indicate that the effects of secondary messengers such as NO are mediated, at least in part, by cyclic guanosine monophosphate (cGMP) and extracellular signal-regulated kinase 1,2 (ERK 1,2) pathway. ${ }^{29}$ Interestingly, the monoamine oxidase-B inhibitor L-deprenyl (Selegiline), effective in treating Parkinson's disease (PD), has neuroprotective properties related to increased production of $\mathrm{NO}$ in brain tissue and cerebral vessels enhancing cerebral blood flow. ${ }^{30}$ These observations collectively suggest new therapeutic applications for NO-donating compounds in vascular and other neurodegenerative diseases. ${ }^{31}$ Because of these novel actions of $\mathrm{NO}$, the possibility that $\mathrm{NO}$, released from NO-donors, serves as a neuronal cell-survival promoting molecule to protect cells from oxidative damage was evaluated. We challenged the neuronal cell line PC12 pheochromocytoma cells to oxidative stress by means of acute exposure to an oxidative agent, hydrogen peroxide, ${ }^{32}$ in the presence of various amounts of NO releasing compound. We report herein findings from these in vitro studies.

\section{EXPERIMENTAL}

\section{Materials}

Toluene (Fisher), and $N, N$-dimethylacetamide (DMAC) (Aldrich), were dried over calcium hydride and then distilled at reduced pressure. Diphenyl sulfone (DPS) (Aldrich) was recrystallized from acetone. All $\alpha$ (alpha), $\omega$ (omega), diamines, purchased from Aldrich, were purified either by distillation (containing up to five methylene units) under reduced pressure. The solid diamines, (with six to twelve methylene units) were recrystallized from low boiling (b.p $35^{\circ} \mathrm{C}-50{ }^{\circ} \mathrm{C}$ ) ligroin and then dried in a vacuum oven at room temperature. DFDNB (Aldrich) was recrystallized from anhydrous ether. All other chemicals were used as received. All reagents used for cell culture studies were purchased from ATCC or Fisher Scientific corporations. Griess Reagent ${ }^{33}$ was purchased from Oxford Biomed Inc.

\section{Measurements}

Proton and ${ }^{13} \mathrm{C}$ NMR spectra of the model compounds in $\mathrm{CDCl}_{3}$ were recorded using a Varian Mercury-500 MHz or a Varian Mercury-300 instrument. IR spectra were obtained with a Nicolet DxB FT-IR spectrophotometer using thin films of the materials on sodium chloride plates. Mass spectra were obtained using a Hewlett-Packard Model 5995A Gas Chromatograph/Mass Spectrometer (GC/MS) with an ionization potential of 70 electron volts or a Bruker Auto Flex MALDITOF instrument using 2,5-dihydroxybenzoic acid (DHB) as the matrix for high molecular weight model compounds.

\section{Measurement of Concentration of Released NO}

Deionized water $(18 \mathrm{~mL})$, followed by $2 \mathrm{~mL}$ of PBS were added to a $50 \mathrm{~mL}$ round-bottomed flask, fitted with a magnetic stirrer. Cadmium pellets $(1 \mathrm{~g})$, previously washed in $0.1 \mathrm{M}$ hydrochloric acid and $0.1 \mathrm{M}$ ammonium hydroxide, were then added to the reaction vessel. Nitrosated material $(50-100 \mathrm{mg}$ ) was added to the vessel and stirring was initiated. The first two measurements were conducted at the $5 \mathrm{~min}$ and the 10 min, followed by measurements at $10 \mathrm{~min}$ intervals for one hour, then $30 \mathrm{~min}$ intervals for $3 \mathrm{~h}$, and at $60 \mathrm{~min}$ intervals for $12 \mathrm{~h}$.

A general procedure for monitoring the concentrations of released $\mathrm{NO}$ at different time intervals from $\mathrm{N}$-nitrosamines is described below. A $250 \mu \mathrm{L}$ sample of heterogeneous $N$-nitrosamine containing aqueous mixture was transferred to a vial. The sample was then centrifuged for $5 \mathrm{~min}$ at $13000 \mathrm{rpm}$ to completely separate the insoluble solid from the aqueous solvent. To $50 \mu \mathrm{L}$ samples of the aqueous layer were placed into separate wells on a well plate. To each well, $50 \mu \mathrm{L}$ of deionized water, $50 \mu \mathrm{L}$ of color reagent I (sulfanilamide), and $50 \mu \mathrm{L}$ of color reagent II $(N-1$-napthylethylene diamine dihydrochloride) were added. The concentration of the nitrite in the solution of each well was measured using a micro plate reader (Dynatech Laboratories Minireader II) fitted with a $570 \mathrm{~nm}$ filter. The instrument was calibrated using standard solution, which consisted of $100 \mu \mathrm{L}$ of deionized water, $50 \mu \mathrm{L}$ of color reagent I, and $50 \mu \mathrm{L}$ of color reagent II.

\section{General Procedure for Synthesis of Compounds C4-C7}

Although described elsewhere, ${ }^{14}$ a detailed reaction procedure for the synthesis of C7 is provided. Compounds C4-C6 were prepared in a similar manner.

The reaction apparatus consisted of a three-necked, $100 \mathrm{~mL}$ round-bottomed flask, a nitrogen inlet, a thermometer, a magnetic stirring bar, and a Dean-Stark trap fitted with a condenser. Heptylamine (1.115 g, $0.01 \mathrm{~mol})$, 1,5-difluoro-2,4dinitrobenzene $(1.020 \mathrm{~g}, 0.005 \mathrm{~mol})$, and anhydrous potassium carbonate $(2.20 \mathrm{~g}$, excess) were transferred in to the reaction vessel. The weighing pans were washed with DMAC $(20 \mathrm{~mL})$ and toluene $(20 \mathrm{~mL})$, with the solvent flowing directly into the reaction vessel. The reaction mixture was heated using an external oil bath to $60{ }^{\circ} \mathrm{C}$, and the reaction was allowed to continue with stirring at this temperature for $30 \mathrm{~min}$. The temperature of the reaction mixture was gradually raised to $150{ }^{\circ} \mathrm{C}$ over a period of $2 \mathrm{~h}$. Water, the by-product of the reaction, was removed by azeotropic distillation with toluene through the Dean-Stark trap. The reaction vessel was cooled to room temperature. Tetrahydrofuran (THF) $(25 \mathrm{~mL})$ was added to the reaction mixture, which was then filtered. The filtrate was evaporated at reduced pressure to remove solvents. The residue was dissolved in dichloromethane, filtered, and washed twice with water. The organic layer was dried over anhydrous magnesium sulfate, filtered, and the filtrate was evaporated using a rotary evaporator. The crude residue was recrystallized from dichloromethane/hexane to yield the desired compound in $59.8 \%$ yield. 


\section{General Procedure for the Preparation of $\mathrm{N}$-Nitrosamines C4'-C7'}

A detailed reaction procedure for the synthesis of $\mathrm{C}^{\prime}$ is provided. Model compounds $\mathrm{C}^{\prime}-\mathrm{C}^{\prime}$ were prepared in a similar manner.

Compound $\mathrm{C} 4(0.057 \mathrm{~g})$ was dissolved in $4 \mathrm{~mL}$ of tetrahydrofuran (THF) in a $25 \mathrm{~mL}$ round-bottomed flask, fitted with magnetic stirring bar. Acetic acid $(6 \mathrm{~mL})$ was added to adjust the $\mathrm{pH}$ to $2-3$. The reaction vessel was immersed in a salt-ice bath, and the temperature of the reaction mixture was monitored using a thermometer. Sodium nitrite $(0.12 \mathrm{~g}$, molar ratio $8: 1$ to $\mathrm{C} 4$ ) was added after the temperature of the reaction mixture had reached $0{ }^{\circ} \mathrm{C}$, and the nitrosation reaction was carried out for $8 \mathrm{~h}$ with constant stirring at this temperature in the dark. At the completion of the reaction, 4M sodium hydroxide solution $(27 \mathrm{~mL})$ was added to the reaction mixture, while maintaining the temperature at $0{ }^{\circ} \mathrm{C}$, to raise the $\mathrm{pH}$ of the reaction mixture to $9-10$. The reaction mixture was then extracted twice with dichloromethane $(40 \mathrm{~mL}+20 \mathrm{~mL})$, followed by $10 \%$ aqueous sodium bicarbonate solution $(20 \mathrm{~mL})$. The organic layer was dried over anhydrous magnesium sulfate, filtered, and the filtrate was evaporated under reduced pressure to yield a yellow solid. The product was then stored in sealed vials under argon atmosphere at $4{ }^{\circ} \mathrm{C}$.

\section{General Procedure of Synthesis of Polymers D4-D10}

A detailed reaction procedure for the synthesis of D4 is provided. Polymers D5-D10 were prepared in a similar manner. ${ }^{14}$

The reaction apparatus consisted of a four-necked, $100 \mathrm{~mL}$ round-bottomed flask fitted with an overhead mechanical stirrer, a nitrogen inlet, a thermometer, and a Dean-Stark trap fitted with a condenser. An oil bath was used as the external heat source. The monomers 1,4-Diaminobutane $(0.8845 \mathrm{~g}$, 0.010 moles) and DFDNB (2.0504 g, 0.010 moles) were transferred carefully into the reaction vessel. Anhydrous potassium carbonate $(2.0803 \mathrm{~g}, 0.015$ moles, excess), and diphenyl sulfone $(20 \mathrm{~g})$ were then added. The weighing pans were washed with toluene $(20 \mathrm{~mL})$, with solvent flowing directly into the reaction vessel. The color of the reaction mixture turned deep yellow. The temperature rose to approximately $35^{\circ} \mathrm{C}$ from room temperature indicating that the initial reaction was exothermic. The reaction mixture was heated to $60^{\circ} \mathrm{C}$ and the reaction was allowed to continue at this temperature for $30 \mathrm{~min}$. The temperature of the reaction mixture was gradually increased to $150{ }^{\circ} \mathrm{C}$. Water, the by-product of reaction, was removed by azeotropic distillation with toluene through the Dean-Stark trap over a period of $1 \mathrm{~h}$, and toluene was then removed via the trap. Temperature was increased gradually to $190{ }^{\circ} \mathrm{C}$ over a period of $2 \mathrm{~h}$, then to $220^{\circ} \mathrm{C}$ and held at that temperature for a period of $30 \mathrm{~min}$. The color of the reaction mixture became deep reddish brown gradually, and the viscosity of the reaction mixture increased. The hot reaction mixture was poured into a rapidly stirring mixture of acetone and acetic acid (80/20, v/v), and the precipitated polymer was collected by filtration. The polymer was then extracted using a
Sohxlet extractor with acetone, water and acetone, in that order, to remove residual potassium carbonate and diphenyl sulfone to give the final product.

\section{General Procedure for the Preparation of Polymeric $\mathrm{N}$ - Nitrosamines, D4' -D10' $^{\prime}$}

A detailed reaction procedure for the synthesis of $\mathrm{D}^{\prime}$ is provided. Polymers D5'-D10' were prepared using similar procedures.

Polyamine D4 $(0.107 \mathrm{~g})$ was dissolved in $20 \mathrm{~mL}$ of aqueous concentrated sulfuric acid. The solution was filtered through glass wool and the filtrate was transferred to a $50 \mathrm{~mL}$ roundbottomed flask fitted with a magnetic stir bar. The solution was cooled to $-20^{\circ} \mathrm{C}$ in a dry ice/acetone bath and sodium nitrite $(0.234 \mathrm{~g}, 8$ molar equivalents) was added to the solution with constant stirring. The temperature of the reaction vessel was allowed to slowly rise to room temperature over a period of $8 \mathrm{~h}$, and the reaction was allowed to continue at that temperature for $6 \mathrm{~h}$. The color of reaction mixture changed from golden yellow to orange red. The reaction mixture was poured slowly into an ice/water mixture $(\sim 500 \mathrm{~mL})$ to precipitate the $N$-nitrosated polymer. The product was collected via vacuum filtration and rinsed with copious amount of water. It was then stored in a vial under argon at $4{ }^{\circ} \mathrm{C}$ to remove residual water and to prevent release of NO.

\section{General Procedure for Cell Culture Study}

The neuronal cell line PC12 cells (ATCC) were grown at $37^{\circ} \mathrm{C}$ in ATCC-formulated $\mathrm{F}-12-\mathrm{K}$ medium with $2.5 \%$ fetal bovine serum (FBS), 15\% horse serum and $1 \%$ Penicillin Streptomycin (100 I.U./mL Penicillin $100 \mu \mathrm{g} / \mathrm{mL}$ Streptomycin). Cell death was induced by replacement of the medium with Dulbecco/Vogt modified Eagle's minimal essential medium (DMEM) and $\mathrm{H}_{2} \mathrm{O}_{2}(500 \mathrm{mM})$ for $4 \mathrm{~h}$ and then switched to $\mathrm{H}_{2} \mathrm{O}_{2}$ free cell culture medium in the absence, or in combination with, NO releasing compound $(0.0,0.02,0.2$, $2.0 \mathrm{mg} / \mathrm{mL})$. Cell viability was determined at 24 or $48 \mathrm{~h}$ of NO exposure. Viable cells were identified by 3-(4,5-Dimethylthiazol-2-yl)-2,5-diphenyltetrazolium bromide (MTT) cell proliferation assay (ATCC) using the absorbance reading.

\section{RESULTS AND DISCUSSION}

\section{Preparation and Characteristics of Model Compounds C4- C7 and $\mathbf{C 4}^{\prime}-\mathbf{C 7}^{\prime}$}

In our preceding communication we have reported the preparation and properties of the model compounds C4-C7 in detail. ${ }^{14}$ These compounds were prepared (Scheme 1) by the nucleophilic aromatic displacement $\left(S_{N} A r\right)$ reactions of the fluorine atoms of DFDNB by aliphatic amines containing four to seven methylene units. The reactions were carried out in DMAC at elevated temperature $\left(125^{\circ} \mathrm{C}\right)$ in the presence of anhydrous potassium carbonate. ${ }^{34}$ Single crystal X-ray analyses, which will be reported elsewhere, coupled with spectroscopic measurements, helped establish the structures of these model compounds. The ${ }^{1} \mathrm{H}$ NMR of compound C5 is shown in 

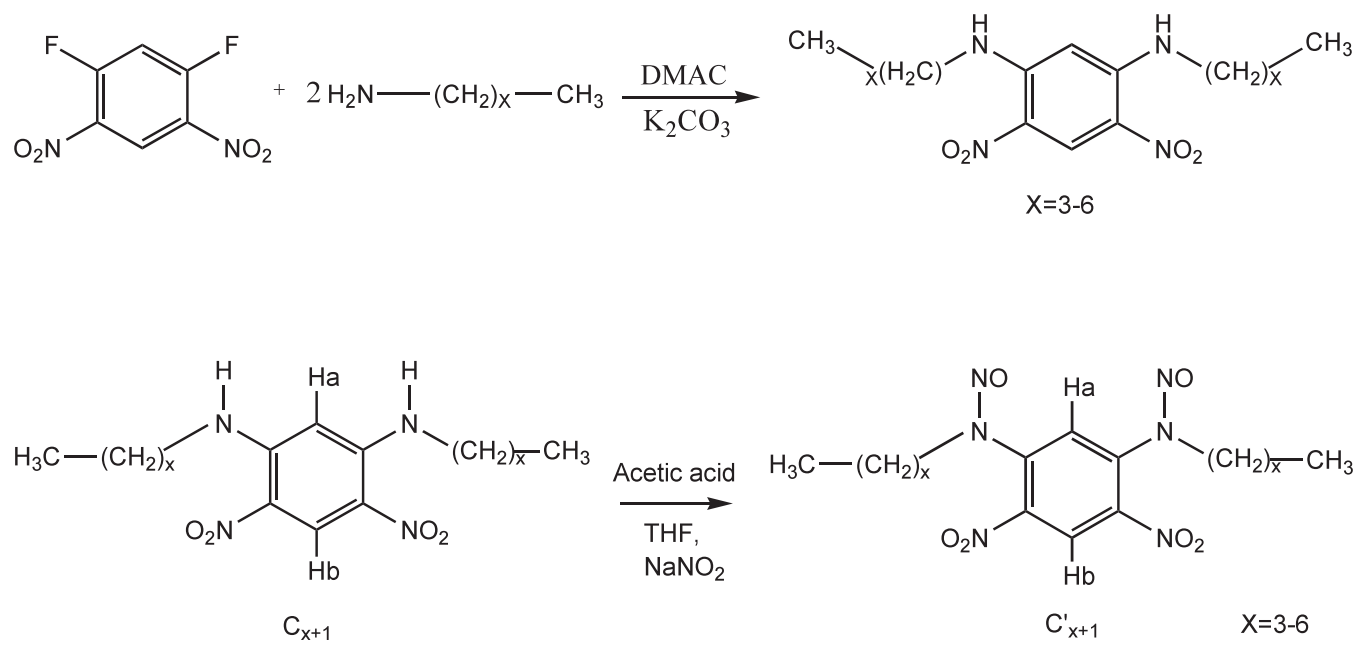

Scheme 1. Preparation and Nitrosation of compounds C4-C7.

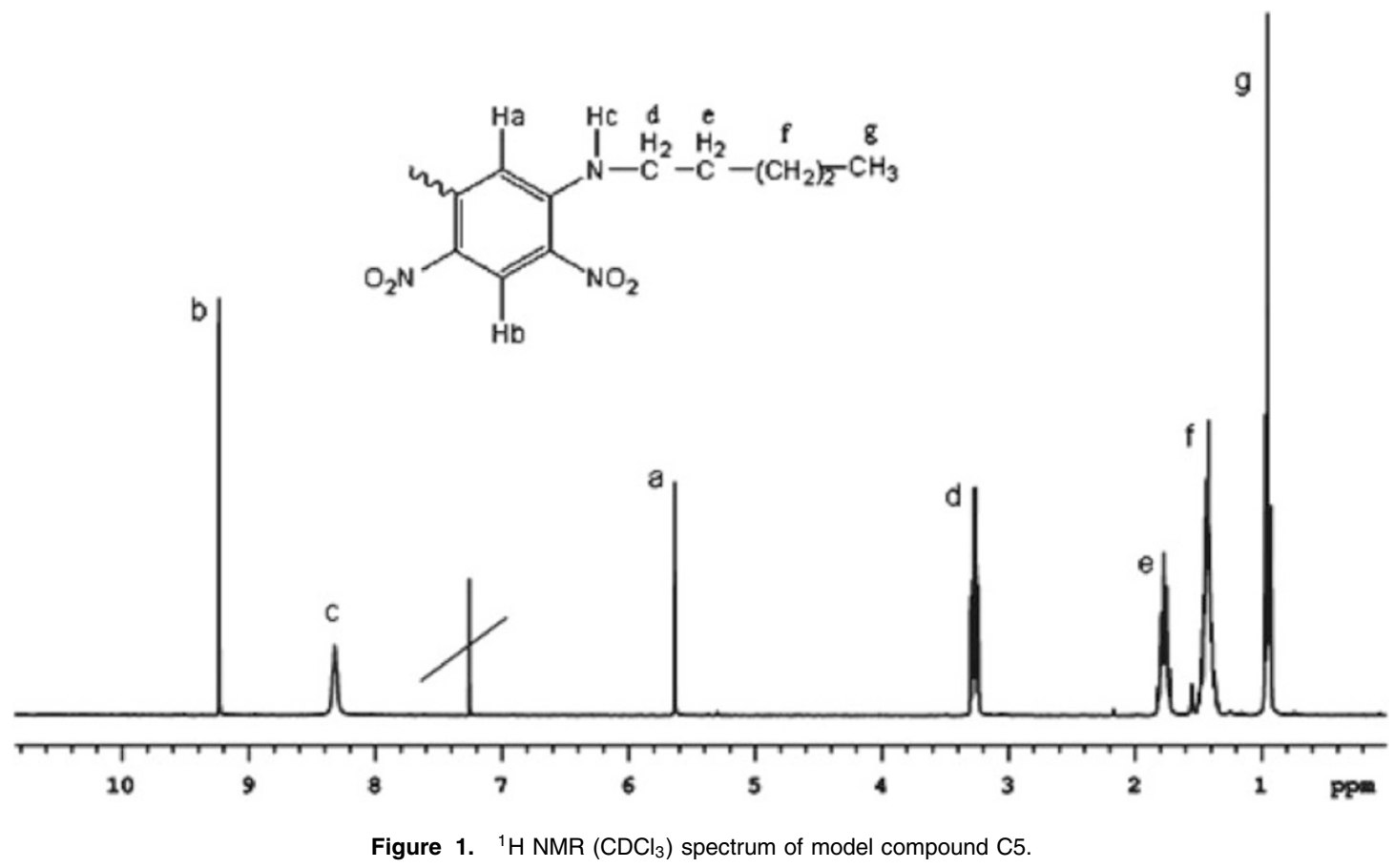

Figure 1. An examination of Figure 1 indicates the vastly different chemical environments of the two aromatic protons. Furthermore, the absorbance due to the two methylene units adjacent to the secondary amine groups appear at $\sim 3.2 \mathrm{ppm}$ significantly more downfield (a consequence of close proximity to the substituted benzene ring) than the remainder of the aliphatic protons.

The nitrosation reactions of the secondary amine moieties present in the model compounds were carried out in a mixture of acetic acid and THF (Scheme 1). The acetic acid-THF solvent system offered several advantages over concentrated sulfuric acid alone, including the ease of operation, fast nitrosation rate, and high purity of the product. The work up procedure, outlined in the experimental section, was carried out rapidly in order to minimize the loss of nitric oxide.

\section{Preparation and Characteristics of Polymers D4-D10 and D4' -D10'}

As described earlier, ${ }^{14}$ polymers D4-D10 were prepared by the reactions of appropriate aliphatic diamines with DFDNB in toluene and DPS at elevated temperatures (Scheme 2). It was necessary to carry out these polymerization reactions at temperatures exceeding $195^{\circ} \mathrm{C}$ in order to obtain moderate to high molecular weight polymers. The extraordinary solvent resistance of these polymers were ascribed to both inter and intramolecular H-bonding interactions. These polymers were only soluble in aqueous concentrated mineral acids with large counter-ions, including sulfuric, nitric, and perchloric acids. The nitrosation of the secondary amine groups present in the polymer repeat units were conducted in aqueous concentrated sulfuric acid (Scheme 2). The nitrosated polymers were 


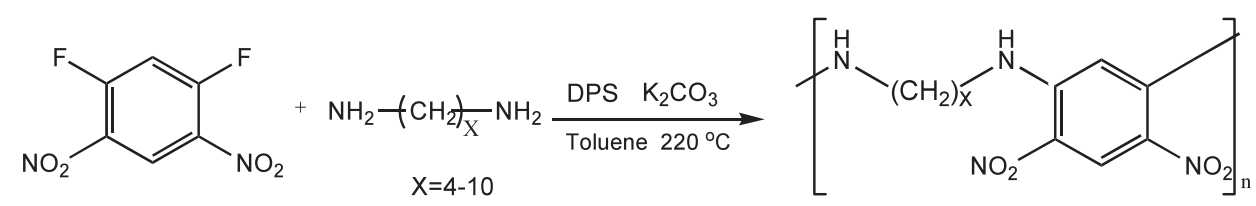<smiles></smiles>

Dx

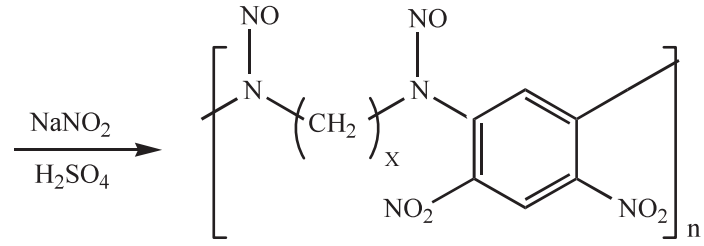

Dx'

$x=4-10$

Scheme 2. Preparation and Nitrosation of polymers D4-D10.

washed with copious quantities of ice-cold water to remove residual acids and then stored at low temperature to remove residual water. It is important to point out that loss of NO is unavoidable during the isolation of both nitrosated model compounds, $\mathrm{C}^{\prime}-\mathrm{C} 7^{\prime}$, and the polymeric analogs, $\mathrm{D} 4^{\prime}-\mathrm{D} 10^{\prime}$. Therefore, it was essential to estimate the degree of nitrosation for each of these compounds.

\section{Measurements of Concentration NO Content in $\mathrm{C4}^{\prime}-\mathrm{C7}^{\prime}$ and $\mathrm{D4}^{\prime}-\mathrm{D} 10^{\prime}$ and Released NO}

$N$-nitrosated model compounds release NO readily in solution. This precluded the use of NMR analyses to measure the conversion of $-\mathrm{NH}$ - to N-NO moiety. Nevertheless, it was useful in eliminating the remote possibility of nitrosation of the benzene ring. The ${ }^{1} \mathrm{H}$ NMR spectrum of a freshly prepared sample of $\mathrm{C6}^{\prime}\left(\mathrm{CDCl}_{3}\right)$ exhibited singlets at 5.64, 6.42, and $6.78 \mathrm{ppm}$ due to the ring proton $\mathrm{H}_{\mathrm{a}}$ (Scheme 1, and Figure 1). These three signals can be ascribed to benzene ring protons flanked by two non-nitrosated, one nitrosated and one nonnitrosated, and two nitrosated secondary amine moieties. This spectroscopic evidence, in addition to the fact that the benzene ring is highly deactivated after the fast nitrosation of the amine moieties, confirmed the absence of a NO moiety on the benzene ring. Furthermore, the absorbances due to the proton $\mathrm{H}_{\mathrm{b}}$ appeared at $9.25,9.18$, and $9.17 \mathrm{ppm}$ respectively. It is likely that these upfield shifts $(9.18$ and $9.17 \mathrm{ppm})$ were due to the partial and complete loss of $\mathrm{H}$-bonding between the $\mathrm{NH}$ and the nitro groups, after the partial conversion of the $\mathrm{NH}$ to $\mathrm{N}$ NO moieties.

$\mathrm{UV}$-vis spectroscopy was used to ascertain the presence of nitroso groups also. Strong absorption at $\sim 242 \mathrm{~nm}$ (chloroform) was indicative of the conversion of $\mathrm{NH}$ moieties to Nitrosamines. ${ }^{35}$ However, as discussed above the inherent instability of these compounds in solution precluded further use of UV-vis analyses.

Therefore, IR spectroscopy was used to ascertain the formation of nitrosamines and to monitor the extent of nitrosation. The N-N bond of nitrosamines exhibit a strong absorbance at $\sim 1040 \mathrm{~cm}^{-1} .{ }^{36}$ This is evident from an examination of the IR spectrum of $\mathrm{C}^{\prime}$ (Figure $2 \mathrm{~b}$ ). The other strong absorbance $\sim 1450 \mathrm{~cm}^{-1}$ due to $\mathrm{N}=\mathrm{O}$ group was difficult to identify definitively due to the presence of aromatic nitro groups. IR spectra were used to determine the extent of nitrosation in the following manner. After nitrosation, the intensity of the absorbance due to the secondary amine group at $3372 \mathrm{~cm}^{-1}$ decreases. Thus the conversion from secondary amines into $N$-nitrosated materials can be easily determined by the change of the ratios of the absorbances of $\mathrm{N}-\mathrm{H}$ and the $\mathrm{C}=\mathrm{C}$ groups $\left(\sim 1620 \mathrm{~cm}^{-1}\right)$ (benzene ring) in the IR spectra. These are illustrated below for one of the model compounds, C7, (Figure 2a) and that of the partially nitrosated product, $\mathrm{C7}^{\prime}$ (Figure 2b). These spectra were obtained by casting a thin film of these compounds from a solution in dichloromethane on the salt plates. This procedure worked well for the model compounds but failed with polymeric counterparts due to the insolubility of the starting materials, D4-D10, in volatile organic solvents. The nitrosated materials D4'-D10', were soluble in highly polar solvents, including dimethyl sulfoxide and dimethylacetamide. They exhibited limited solubility in dichloromethane-a consequence of moderate loss of inter and intra-chain H-bonding interactions. It was possible, however, to circumvent this difficulty by comparing the IR spectrum of the nitrosated polymer with that of the corresponding model compound. The degrees of nitrosation for both model compounds and that of the polymers are listed in Table I below. An examination of these data suggests that the extent of nitrosation range is $55 \%$ to $80 \%$.

The concentration of released NO was measured in PBS over a period of $\sim 30 \mathrm{~d}$ using colorimetric technique. While more sensitive fluorometric techniques are available, the reagents needed for these analyses are less economical than Griess reagent. ${ }^{37}$ The release profiles obtained from $\mathrm{C}^{\prime}-\mathrm{C}^{\prime}$ and the polymers D4'-D10' are displayed in Figure $3 \mathrm{a}$ and $3 \mathrm{~b}$ respectively. An examination of these two figures indicates the following: First, except for polymer D4', the general patterns of NO release profiles of the polymers and those of the model 


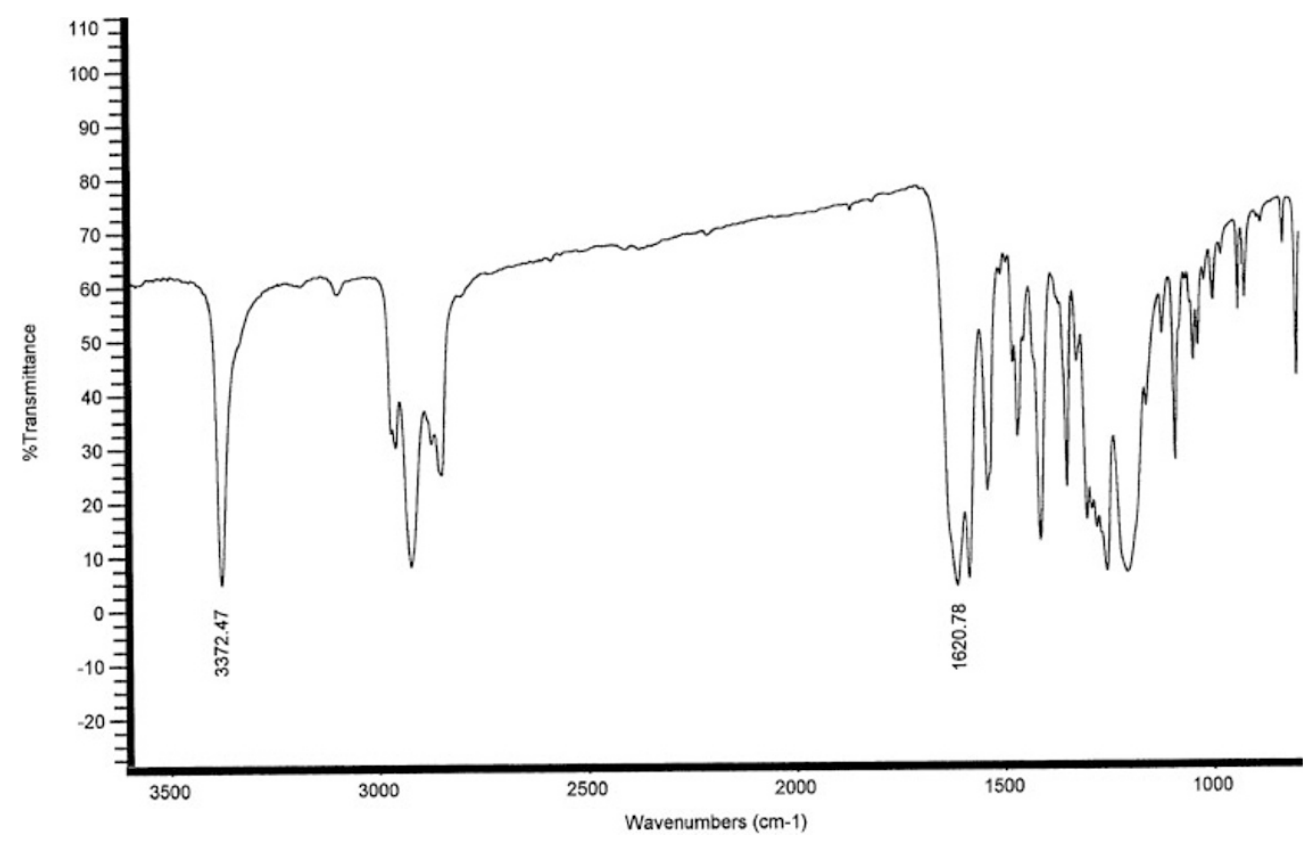

(a)

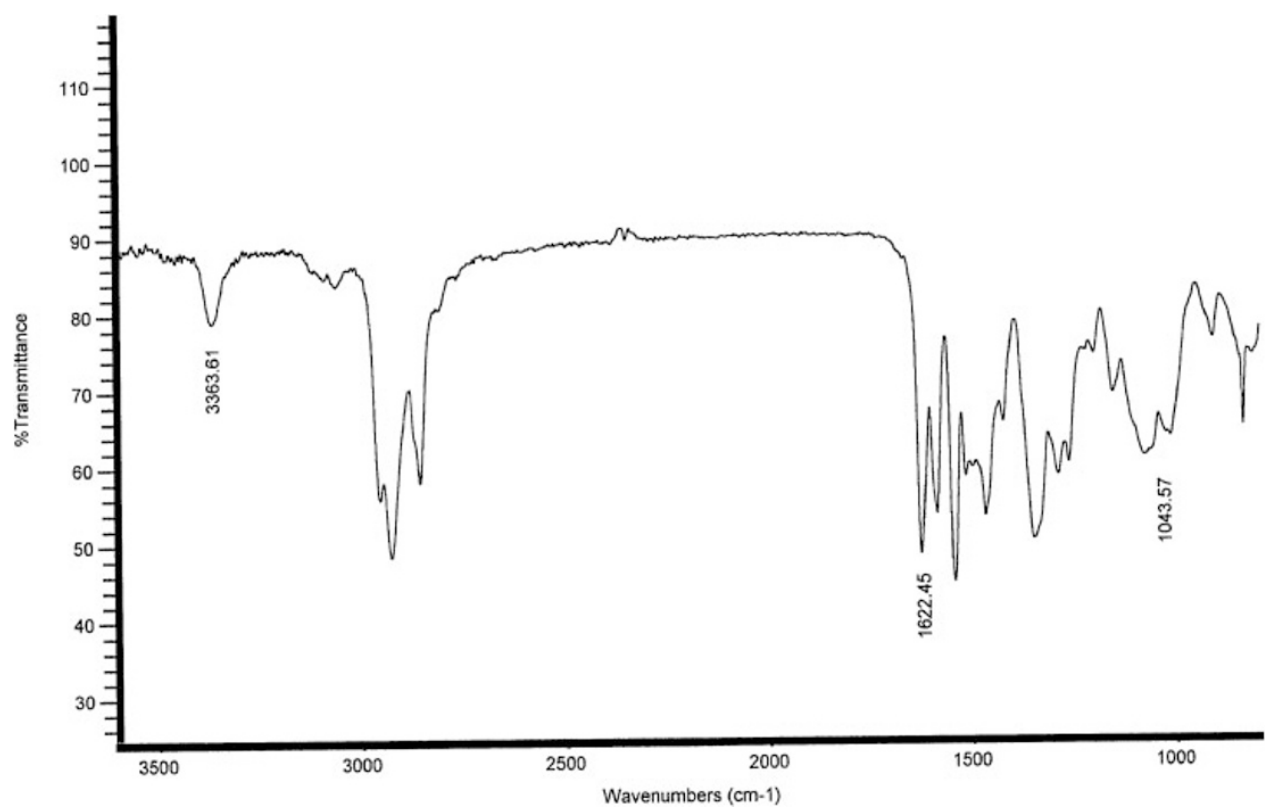

(b)

Figure 2. a) IR spectrum of $C 7$ b) IR spectrum of $C 7^{\prime}$.

compounds are similar. Second, NO release occurs in three distinct phases; in the initial phase it is extremely rapid, which is followed by a slower release phase, and in the third stage, NO release slows down considerably. Third, during this period $\sim 1 \%$ of the total $\mathrm{NO}$ present in the polymers and from $1 \%$ to $3 \%$ of NO content of the model compounds (Table I), is released. Fourth, barring D4', the rate of NO release is strongly dependent on the length of the spacer methylene units. It is possible to assume that within experimental errors, the NOrelease rate increases linearly with increasing aliphatic chain lengths (Figure 4a and 4b). Fifth, the measured "apparent" half-lives, $t_{1 / 2} \mathrm{~s}$, range from $28 \mathrm{~h}$ to $88 \mathrm{~h}$ for the nitrosated polymers and from $38 \mathrm{~h}$ to $81 \mathrm{~h}$ for the nitrosated model compounds. Sixth, as illustrated in Figure $5 \mathrm{~b}$ below, the "apparent" half-life of the polymers, and that of the model compounds (Figure 5a), decrease asymptotically with the increase in the spacer lengths.

We will address the apparent anomaly associated with the NO release profile of $\mathrm{D}^{\prime}$ ' first, followed by a possible explanation as to why the NO-release rate increases with 


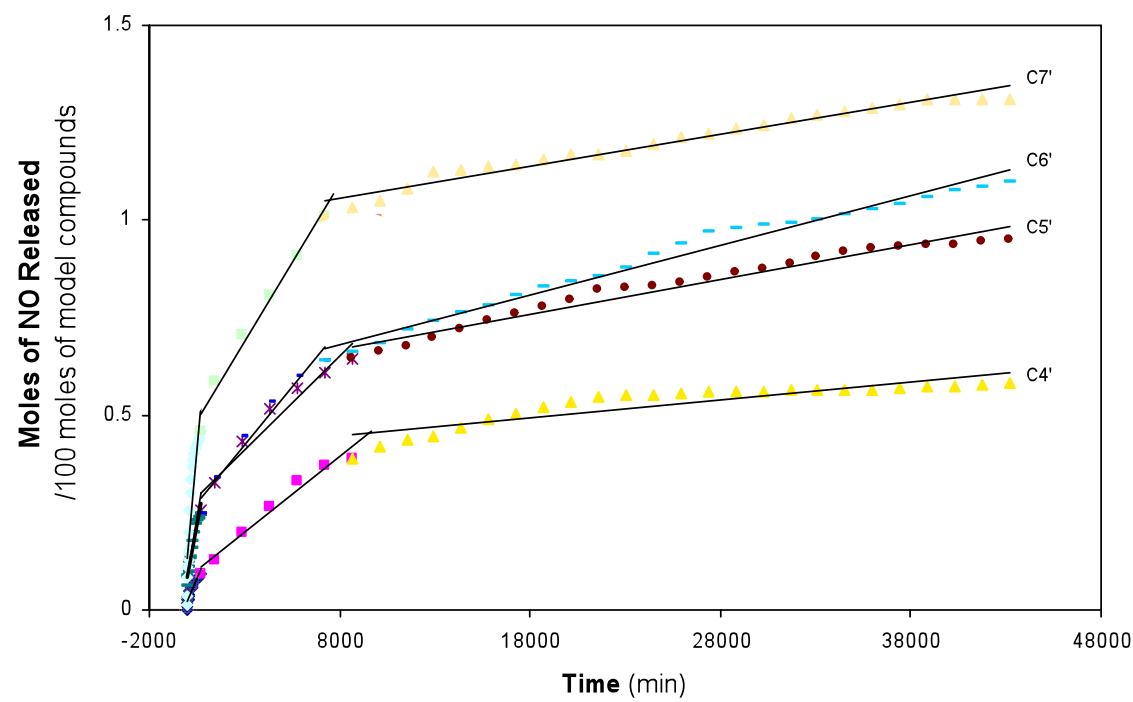

(a)

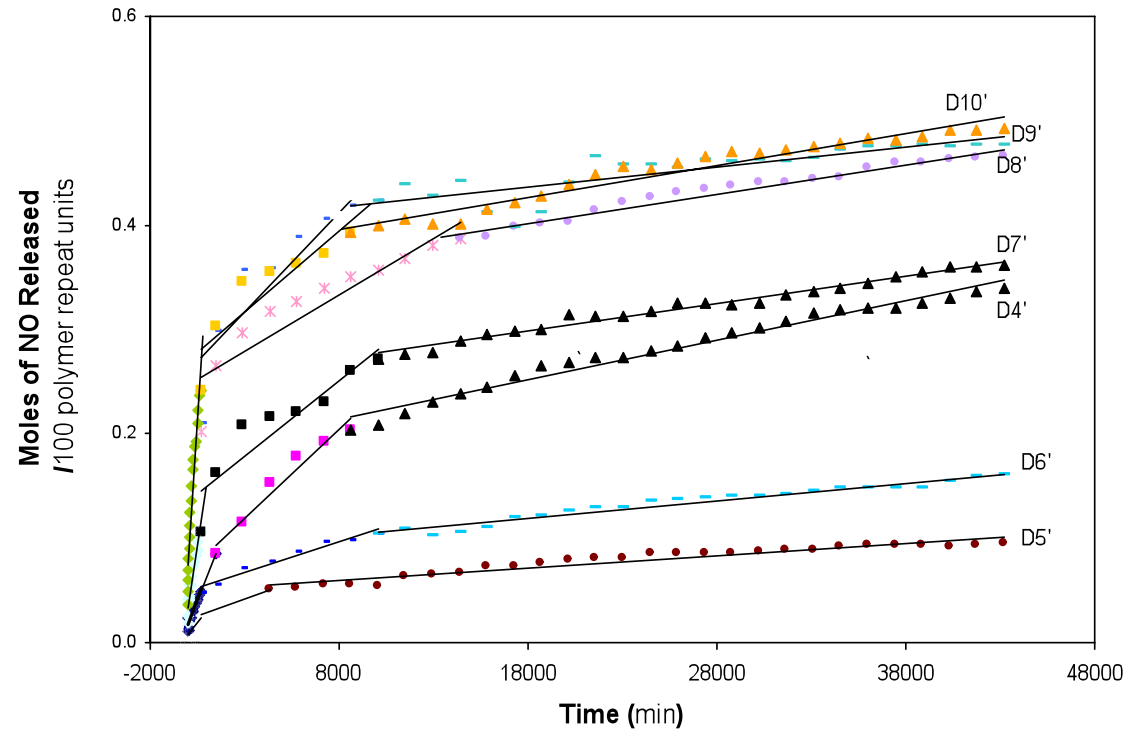

(b)

Figure 3. a) Release Profiles of $C 4^{\prime}-C 7^{\prime}(\sim 30 \mathrm{~d})$ b) Release Profiles of D4'-D10' ( $\left.30 \mathrm{~d}\right)$.

Table I.

\begin{tabular}{cccc}
\hline Polymer & $\begin{array}{c}\text { Percent } \\
\text { Nitrosated }\end{array}$ & $\begin{array}{c}\text { NO released } \\
\text { (mole \%) }\end{array}$ & $\begin{array}{c}\text { Apparent half-life } \\
\text { (Min) }\end{array}$ \\
\hline D4' $^{\prime}$ & 55 & 0.34 & 5277 \\
D5' $^{\prime}$ & 79 & 0.09 & 3960 \\
D6 $^{\prime}$ & 70 & 0.16 & 4971 \\
D7' & 64 & 0.36 & 2064 \\
D8' & 67 & 0.47 & 1031 \\
D9' & 79 & 0.48 & 917 \\
D10' & 76 & 0.49 & 689 \\
Compound & & & \\
C4' & 73 & 0.58 & 4878 \\
C5' & 65 & 0.95 & 3596 \\
C6 $^{\prime}$ & 80 & 1.10 & 4669 \\
C7 $^{\prime}$ & 73 & 1.31 & 2289 \\
\hline
\end{tabular}

increasing aliphatic chain lengths. As reported earlier, ${ }^{14}$ the molecular weight of polymer D4 was relatively low compared to D5-D10. This was evident from the intrinsic viscosity value obtained for D4 in aqueous concentrated sulfuric acid ( 0.17 $\mathrm{dL} / \mathrm{g}$ ), as compared to higher values for the remainder of the polymers prepared from diamines with longer aliphatic chains. Thus, D4 will contain a higher concentration of end groupsaliphatic amines, and aromatic fluorine moieties. During nitrosation reaction, some of these aliphatic primary amines are converted to diazonium salts. The remaining primary amine groups readily displace these groups. This results in a longer polymeric chain via a secondary amine linkage. ${ }^{38}$ After the completion of the nitrosation reactions, one obtains a nitrosated polymer D4" (Scheme 3) with a different structure from what was expected for $\mathrm{D}^{\prime}$. Thus, it is not surprising that the NOrelease profile of D4" resembles that of a polymer in this 


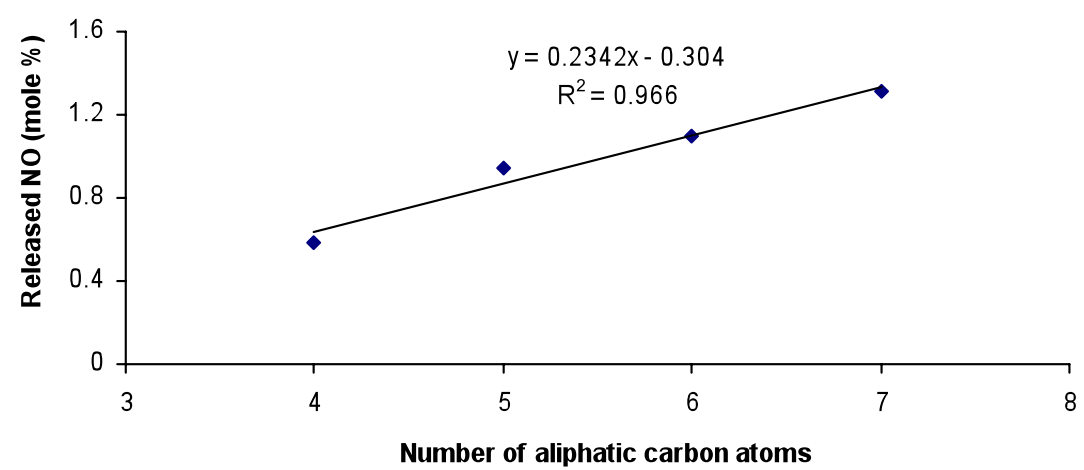

(a)

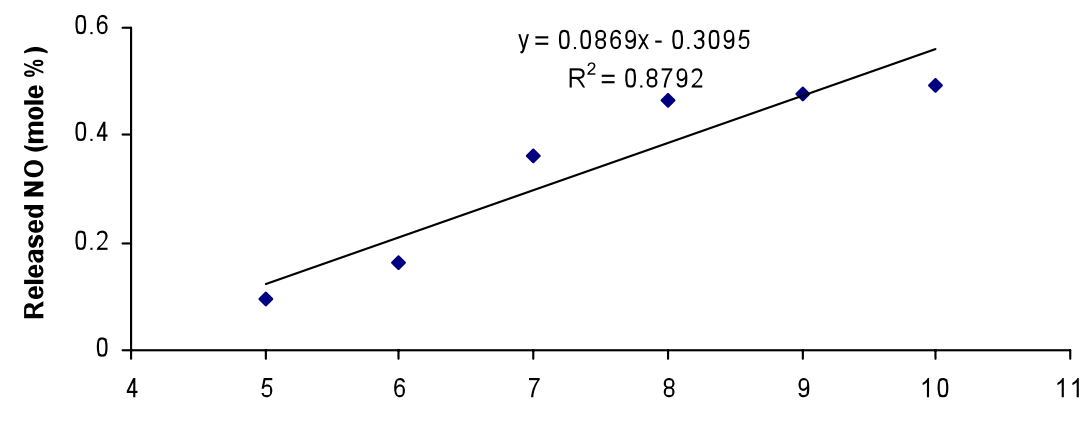

Number of aliphatic carbon atoms

(b)

Figure 4. a) Plot of percent of NO released for $C 4^{\prime}-C 7^{\prime}$ with varying aliphatic chain lengths b) Plot of percent of NO released for D4'-D10' with varying spacer lengths.

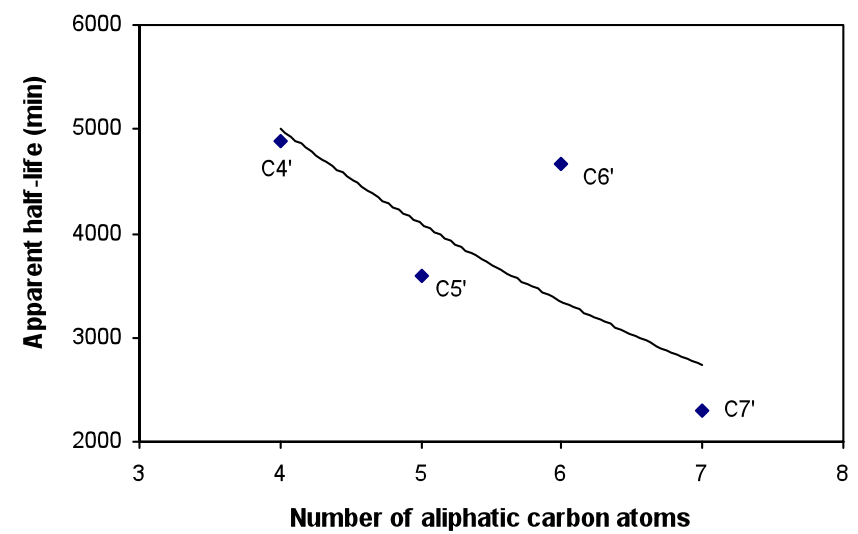

(a)

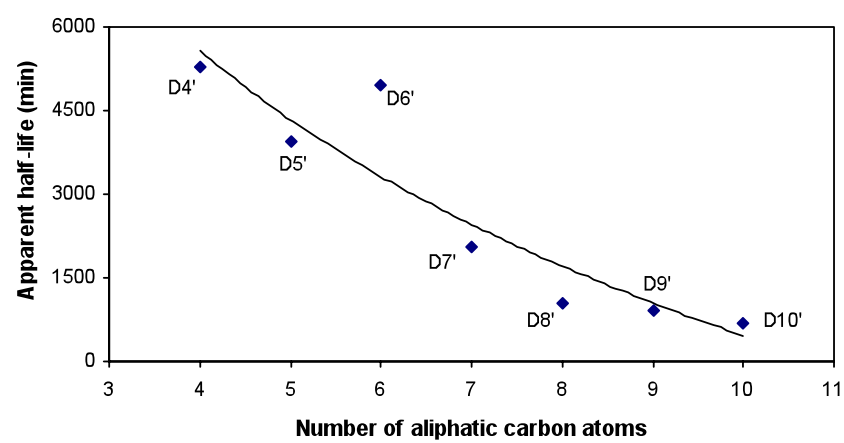

(b)

Figure 5. a) Plot of "Apparent $t_{1 / 2}$ " of $C 4^{\prime}-\mathrm{C} 7^{\prime}$ with varying aliphatic chain lengths b) Plot of "Apparent $t_{1 / 2}$ " of $\mathrm{D} 4^{\prime}$-D10' with varying spacer lengths.

family, with an aliphatic spacer containing more than four methylene units. Furthermore, the experimentally determined amount of released NO from D4" (0.34 mole percent, Table I, Figure $3 b)$ is higher than the extrapolated amount $(\sim 0.04$ mole percent, Figure $4 b$ ). The $-\mathrm{N}-\mathrm{NO}$ group from the newly formed secondary amine group may be the major source of this excess.

The first step of the de-nitrosation reaction involves protonation of the nitrogen atom of the amine moiety. ${ }^{39}$ The protonation step becomes more facile with the reduction of intra-chain electrostatic repulsion, as the secondary amine groups are further removed from one another with increasing aliphatic spacer lengths. This simple explanation as to why denitrosation becomes faster from $\mathrm{C}^{\prime}$ to $\mathrm{C}^{\prime}$, as well as from $\mathrm{D}^{\prime}$ to $\mathrm{D} 10^{\prime}$, may not be the only one; it is possible that structural features other than the one mentioned above may well be operational. A periodic shift in the chain conformations may also be contributing to the pattern, namely the three stages of NO loss. In addition, based on reported data, we believe that the compounds and polymers reported herein are not expected to be potential carcinogens. ${ }^{40}$ 
<smiles>[X]C(C)Nc1cc2c(cc1[N+](=O)[O-])CC(C)(C)C2</smiles>

Dx

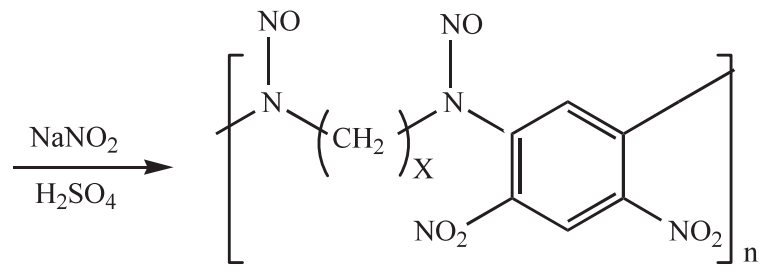

Dx'

$X=4-10$

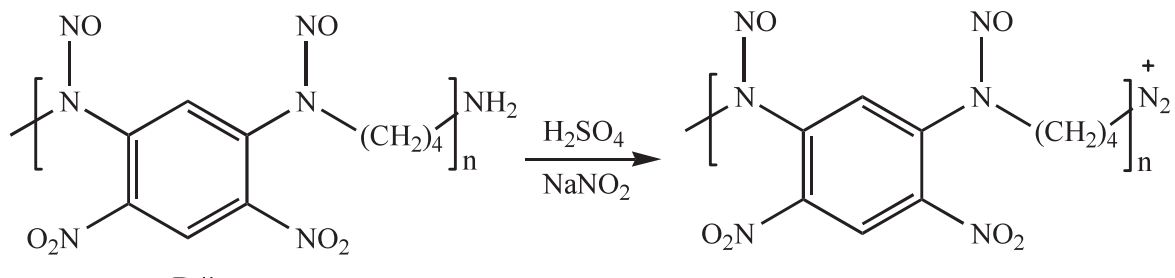

D4'<smiles>CCCCCCN(N=O)c1cc(N([N+](=O)[O-])C(C)(C)C)c([N+](=O)[O-])cc1[N+](=O)[O-]</smiles><smiles>CC(C)(N)CN(N=O)c1cc(N([N+](=O)[O-])C(C)(C)C)c([N+](=O)[O-])cc1[N+](=O)[O-]</smiles>

D4'

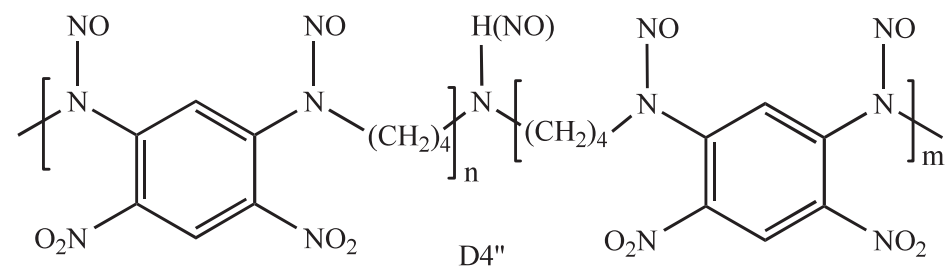

Scheme 3. Conversion of D4' to D4".

\section{Cell Culture}

In order to evaluate the neuroprotective effects of released NO on oxidatively stressed neuronal cell, PC12 pheochromocytoma cells were chosen as the target. This necessitated identifying a nitrosated polymer or a model compound, which can be dissolved in water or a biocompatible solvent. This requirement immediately precluded the use of high molecular weight polymers $\mathrm{D}^{\prime}$-D $10^{\prime}$. These polymers were partially soluble in organic solvents, including halogenated hydrocarbons, and exhibited a high degree of solubility in DMAC. Among the model compounds $\mathrm{C}^{\prime}-\mathrm{C}^{\prime}$, only $\mathrm{C}^{\prime}$ exhibited excellent solubility in triethylene glycol (TEG) at room temperature. This was deemed to be acceptable because TEG is water-soluble and structurally mimics polyethylene glycols, which have been used for pegylation of pharmaceuticals, peptides, enzymes, and proteins. ${ }^{41}$ Cells which had been incubated with hydrogen peroxide for $4 \mathrm{~h}$, were exposed to solutions of C6 in TEG (single concentration), and C6' in TEG at three different concentrations for $24 \mathrm{~h}$ and $48 \mathrm{~h}$. Findings from these studies are illustrated in Figure 6 below. An examination of the figure indicates that at a high concentration of C6' $(2.0 \mathrm{mg} / \mathrm{mL})$, only $70 \%$ (24 h treatment) and $50 \%(48 \mathrm{~h}$ treatment) cell survival was observed in comparison to the control. Similar observations were made when the oxidatively challenged cells were treated with TEG or with a solution of C6 dissolved in TEG $(2 \mathrm{mg} / \mathrm{mL})$. The vehicle, TEG, and a solution of non-NO containing compound C6 were unable to inhibit programmed cell death. Treatment of the cells with solutions of $\mathrm{C}^{\prime}$ in TEG at lower concentrations $(0.2$ or 0.02 $\mathrm{mg} / \mathrm{mL}$ ) led to decrease in neuronal cell death. These findings suggest that that the presence of low concentrations of $\mathrm{NO}$ resulted in a significant reduction in neuronal cell death in PC12 cells previously challenged with $\mathrm{H}_{2} \mathrm{O}_{2}$. On the other hand, the presence of high concentration of NO was delete- 


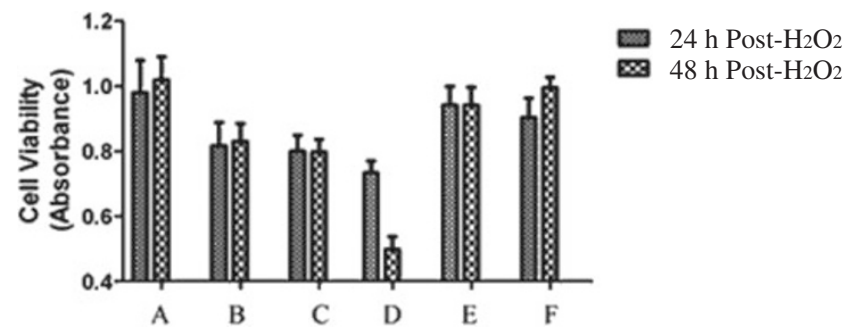

Figure 6. In PC-12 cell culture, there was a significant cell loss after the treatment of $500 \mathrm{mM}$ hydrogen peroxide $\left(\mathrm{H}_{2} \mathrm{O}_{2}\right)$ for $4 \mathrm{~h}$ : (B) (TEG) (0.0), and (C) C6 in TEG $(2 \mathrm{mg} / \mathrm{mL})$ compared with (A) Control [untreated group]. (D) The $\mathrm{H}_{2} \mathrm{O}_{2}$-induced $\mathrm{PC}-12$ cell loss was exacerbated by treatments with $\mathrm{C}^{\prime}$ for $24 \mathrm{~h}$ at a high dose $(2.0 \mathrm{mg} / \mathrm{mL}$ in TEG) [lightly stippled] and $48 \mathrm{~h}$ [darkly stippled bars]. $(E)$ The number of survived PC-12 neurons increased after treatments with a medium dose of $\mathrm{C6}^{\prime}(0.2 \mathrm{mg} / \mathrm{mL}$ in TEG), and (F) a low dose $(0.02 \mathrm{mg} / \mathrm{mL}$ in TEG). Mean living cell counts obtained after low and medium dosage treatments were significantly higher than that of the high dose group at $p<0.05$ by ANOVA.

rious. This is in agreement with earlier observations that exogenous NO donors can act as neuroprotective agent. ${ }^{6}$ This dichotomous response defines a novel type of NO function within the neuronal system.

\section{CONCLUSIONS}

Secondary amine containing polymers with dinitro substituted benzene rings in each repeat unit, as well as model compounds, have been $N$-nitrosated. The partially nitrosated polymers, with lesser degree H-bonding interactions than the polyamine precursors, exhibit a limited degree of solubility in chlorinated hydrocarbons and in dipolar aprotic solvents. The nitrosated materials release nitric oxide in three stages in a controlled and sustained manner. The rate of NO release is strongly dependent on the length of the aliphatic spacer groups between the aromatic moieties. The NO-release profiles of the model compounds parallel those of the corresponding polymers. Cell culture data demonstrated that the novel NO releasing agents can protect neuronal cells from oxidative degeneration.

Acknowledgment. The authors acknowledge President Research Initiative Fund, President's Bridge to Commercialization Fund, and FRCE committee, CMU, and Michigan University Challenge Initiative, State of Michigan. DKM acknowledges a sabbatical support from CMU.

Received: December 16, 2008

Accepted: May 25, 2009

Published: July 15, 2009

\section{REFERENCES}

1. D. A. Wink and J. B. Mitchell, Free Radical Biol. Med., 114, 1136 (1998).

2. W. P. Arnold, C. K. Mittal, S. Katsuki, and F. Murad, Proc. Natl. Acad. Sci. U.S.A., 74, 3203 (1977).

3. L. J. Ignarro, R. E. Byrns, G. M. Burga, and K. S. Wood, Circ. Res.,
61, 866 (1987).

4. a) L. J. Ignarro, G. M. Buga, K. S. Wood, R. E. Byrns, and G. Chaudhuri, Proc. Natl. Acad. Sci. U.S.A., 84, 9265 (1987).

b) R. M. J. Palmer, D. S. Ashton, and S. Moncada, Nature, 333, 664 (1988).

c) M. A. Marletta, P. S. Yoon, R. Iyengar, C. D. Leaf, and J. S. Wishnok, Biochemistry, 27, 8706 (1988).

5. S. S. Gross and M. S. Wolin, Annu. Rev. Physiol., 57, 737 (1995).

6. V. Calabrese, C. Mancuso, M. Calvani, E. Rizzarelli, D. A. Butterfield, and A. M. G. Stella, Nat. Rev. Neurosci., 8, 766 (2007).

7. J. S. Stamler, D. J. Singel, and J. Loscalzo, Science, 258, 1898 (1992).

8. B. Voetsch, R. C. Jin, and J. Loscalzo, Histochem. Cell Biol., 122 353 (2004).

9. A. K. Mack and G. J. Kato, Int. J. Biochem. Cell Biol., 38, 1237 (2006).

10. a) P. G. Wang, X. Ming, X. Tang, X. Wu, Z. Weng, T. Cai, and A. J. Janczuk, Chem. Rev., 102, 1091 (2002).

b) "Nitric Oxide Donors for Pharmaceutical and Biological Applications," P. G. Wang, T. B. Cai, and N. Taniguchi, Ed., Part 1 and Part 3, Wiley-VCH, Weinheim, 2005.

11. a) L. K. Keefer, Annu. Rev. Pharmacol. Toxicol., 43, 586 (2003).

b) Y. Wu and M. E. Meyerhoff, Talanta, 75, 642 (2008).

12. a) A. Ramamurthi and R. S. Lewis, Ann. Biomed. Eng., 26, 1036 (1998).

b) S. Mocanda, R. M. J. Palmer, and E. A. Higgs, Pharmacol. Rev., 43, 109 (1991).

13. Y. Wu and M. E. Meyerhoff, Talanta, 75, 642 (2008).

14. Y. H. Teng, G. Kaminski, Z. Zhang, A. Sharma, and D. K. Mohanty, Polymer, 47, 4004 (2006).

15. a) D. K. Mohanty, U. S. Patent Appl.105,869 (2008).

b) J. D. Oh-Lee and D. K. Mohanty, U. S. Patent Appl.105,857 (2008).

16. Biomedical Frontiers. Nitric Oxide in Parkinson's. 4, (1997), Columbia University Medical Center, http://www.cumc.columbia. edu/news/frontiers/archives/biomed_v4n2_0010.html\#top

17. K. M. K. Boje, Frontiers in Bioscience, 9, 763 (2004).

18. S. J. R. Heales, A. A. J. Lam, A. J. Duncan, and J. M. Land, Neurochem. Res., 29, 513 (2004).

19. K. P. Mohanakumar, I. Hanbauer, and C. C. Chieu, J. Chem. Neuroanat., 14, 195 (1998).

20. A. S. Vidwans, S. Kim, D. O. Coffin, D. A. Wink, and S. J. Hewett, J. Neurochem., 72, 1843 (1999).

21. K. P. Mohanakumara, B. Thomasa, S. M. Sharmab, D. Muralikrishnana, D. Chowdhurya, and C. C. Chiueh, Ann. N.Y. Acad. Sci., 62, 389 (2002).

22. P. Rauhala, A. M. Y. Lin, and C. C. Chiueh, FASEB J., 12, 165 (1998).

23. C. Culmsee, G. Norbert, L. Stefan, R. H. J. D. Bianca, U. Kazuo, K. Susanne, and K. Josef, Mol. Pharmacol., 68, 1006 (2005).

24. R. H. Schaller, Neuron, 14, 893 (1995).

25. G. Schiavo, M. J. S. Gmachi, G. Stenbeck, T. H. Sollner, and J. E. Rothman, Nature, 378, 733 (1995).

26. W. Xu, L. Liu, and I. Charles, FASEB J., 16, 213 (2002).

27. P. Zhou, L. Qian, and C. Iadecola, J. Cereb. Blood Flow Metab., 25, 348 (2005).

28. W. Xu, L. Liu, G. C. Smith, and I. Charles, Nat. Cell Biol., 6, 339 (2000).

29. S. W. Rabkin and M. Y. C. Tsang, Exp. Physiology, 93, 834 (2008).

30. T. Thomas, C. McLendon, and G. Thomas, NeuRoreport, 9, 2595 (1998).

31. Z. M. Gonzalez-Zulueta, A. B. Feldman, L. J. Klesse, R. G. Kalb, J. F. Dillman, L. F. Parada, T. M. Dawson, and V. L. Dawson, Proc. Natl. Acad. Sci. U.S.A., 97, 436 (2000).

32. J. Benedi, R. Arryo, R. Carmen, M. A. Segario, and A. M. Villar, Life Sci., 75, 1263 (2004).

33. a) L. C. Green, D. A. Wagner, J. Glogowski, P. L. Skipper, J. S. 
Wishnok, and S. R. Tannenbaum, Anal. Biochem., 126, 131 (1982). b) D. L. Granger, R. R. Taintor, K. S. Boockvar, and J. Jr. Hibbs, Methods Enzymol., 268, 142 (1996).

c) D. Ricart-Jane, M. Llobera, and M. D. Lopez-Tejero, Nitric Oxide, 6, 178 (2002).

34. a) J. F. Bunnett, E. W. Garbisch, Jr., and K. M. Pruitt, J. Am. Chem. Soc., 79, 385 (1957).

b) N. S. Nudelman, P. M. E. Mancini, R. D. Martinez, and L. R. Vottero, J. Chem. Soc. Perkin Trans., 2, 951 (1987).

c) O. Matsson, J. Persson, B. S. Axelsson, and B. Langstrom, J. Am. Chem. Soc., 115, 5288 (1993).

35. K. Hiramoto, T. Ohkawa, and K. Kikugawa, Free Radical Res., 35, 803 (2001)

36. E. Pretsch, J. Seibl, and W. Simon, in "Tables of Spectral Data for Structure Determination of Organic Compounds" K. Bieman, Ed, Springer, New York, 1981, p I 205.
37. a) H. Kojima, M. Hirotani, N. Nakatsubo, K. Kikuchi, Y. Urano, T. Higuchi, Y. Hirata, and T. Nagano, Anal. Chem., 73, 1967 (2001). b) S. Lepiller, V. Laurens, A. Bouchot, P. Herbomel, E. Solary, and J. Chluba, Free Radical Biol. Med., 43, 619 (2007).

38. D. E. G. Shuker, in "Nitrosamines: toxicology and microbiology," M. J. Hill, Ellis Horwood, Ed., Chichester, UK, 1988, p 48-68.

39. T. Ohwada and M. Uchiyama, J. Synth. Org. Chem. Jpn., 61, 47 (2003).

40. a) B. L. Pool, G. Eisenbrand, R. Preussmann, J. R. Schlehoffer, P Schmezer, H. Weber, and M. Wiessler, Food Chem. Toxicol., 24, 685 (1986).

b) W. Lijinsky, Cancer Metastasis Review, 6, 301 (1987).

c) W. Lijinsky, Cancer Res., 41, 4997 (1981).

41. J. J. Buckley, R. F. Finn, J. Mo, L. A. Bass, and S. V. Ho, "Process Chemistry in the Pharmaceutical Industry," CRC, 2008 p 383. 